\title{
Adsorption of humic acid by amine-modified nanocellulose: an experimental and simulation study
}

\author{
A. Jebali $\cdot$ A. Behzadi $\cdot$ I. Rezapor • \\ T. Jasemizad $\cdot$ S. H. Hekmatimoghaddam • \\ Gh. H. Halvani $\cdot$ N. Sedighi
}

Received: 8 January 2014/Revised: 9 June 2014/ Accepted: 9 August 2014/Published online: 17 September 2014

(C) Islamic Azad University (IAU) 2014

\begin{abstract}
The purpose of this study was to evaluate the adsorption of humic acid (HA) by amine-modified nanocellulose. At first, nanocellulose was synthesized by acid hydrolysis, and then was modified by $N$-(2-aminoethyl)-3aminopropylmethyldimethoxysilane. In the next step, HA and amine-modified nanocellulose were incubated at different conditions $(\mathrm{pH}$, incubation time, temperature, and concentration). Furthermore, we used molecular dynamic (MD) simulation for observation of adsorption at molecular scale. For this purpose, HA and amine-modified
\end{abstract}

A. Jebali $(\bowtie)$

Department of Genetics, Research and Clinical Center for Infertility, Shahid Sadoughi University of Medical Sciences, Yazd, Iran

e-mail: alijebal2011@gmail.com

\section{A. Behzadi · I. Rezapor}

Department of Food Hygiene and Safety, School of Health, Shahid Sadoughi University of Medical Science, Yazd, Iran

T. Jasemizad

Department of Environmental Health, Faculty of Public Health, Shahid Sadoughi University of Medical Sciences, Yazd, Iran

S. H. Hekmatimoghaddam

Department of Laboratory Sciences, School of Paramedicine, Shahid Sadoughi University of Medical Sciences, Yazd, Iran

Gh. H. Halvani

Department of Occupational Health, School of Public Health, Shaheed Sadoughi University of Medical Sciences, Yazd, Iran

N. Sedighi

Department of Food Science, College of Agriculture, Yazd Science and Research Branch, Islamic Azad University, Yazd, Iran nanocellulose were prepared by HyperChem software (Hypercube, Inc., USA), and inserted in Ascalaph Designer 1.8.69 software. Once equilibrium was reached, interactions were simulated for $1,000 \mathrm{ps}$. Finally, different parameters such as interaction energy, potential energy, and root-mean-square displacement (RMSD) were measured. This study demonstrated that the adsorption of HA was $\mathrm{pH}-$, temperature-, dose-, and time-dependent. Based on simulation results, the interaction energy was reduced, but potential energy and RMSD were increased at the final stage of simulation, which indicated the adsorption of HA. The authors suggest amine-modified nanocellulose for removal of HA in wastewater.

Keywords Humic acid · Adsorption - Amine-modified nanocellulose $\cdot$ Experimental $\cdot$ Simulation $\cdot$ Wastewater

\section{Introduction}

Various pollutants may exist in water, which decrease the quality of environmental water, and affect the health of human population and animals (Jonglertjunya and Lertchutimakul 2012). Among the environmental harmful pollutants, humic substances (HSs) are very important, which are formed by decomposition of plant and animal biomass. Regarding the chemical structure, they have a skeleton of aromatic units with different functional groups (e.g., carboxyl, phenolic, hydroxyl, and quinine). HSs are categorized into three compounds based on solubility, including humic acids (HAs), fulvic acids (FAs), and humans (Trump et al. 2006). HSs can cause different environmental and health problems including: (1) undesirable color and taste, (2) binding to heavy metals and biocides which yield new toxic materials, (3) reaction with 
chlorine to form potentially carcinogenic compounds (e.g., trihalomethane), and (4) reduction of adsorption rate and equilibrium capacity of other compounds (Giasuddin et al. 2007). To remove HA, different techniques have been studied including ion exchange, sorption, reverse osmosis, ultra-filtration, flotation, bio-flocculation, electro-coagulation, and chemical oxidation (Bazrafshan et al. 2012).

Moreover, activated carbon (Terdkiatburana et al. 2008), minerals (Davis and Gloor 1981; Liang et al. 2011), montmorillonite (Lin and Juang 2002), zeolite (Wang et al. 2008), and other adsorbents have been used to remove HA from wastewater. It must be mentioned that these adsorbents have different capacities, kinetics, and isotherms. It has been shown that various parameters can affect HA adsorption, such as $\mathrm{pH}$, salt levels, particle size, and molecular weight of HA, initial concentration of HA and adsorbent, incubation time, and temperature (Qin et al. 2012). Since there are various functional groups on the HA, different adsorption mechanisms (e.g., electrostatic, hydrogen band, hydrophobic force, etc.) might be involved in case of HA adsorption.

Although the HA adsorbents have good efficacy, some problems have been observed. For example, activated carbon is not suitable for HA with high molecular weight (Moussavi et al. 2011). On the other hand, zeolite and montmorillonite have heavy metal oxide which may be released during adsorption. Heavy metal oxides (e.g., $\mathrm{TiO}_{2}$ ) have cytotoxicity and can release toxic ions. The problems are remarkable, especially for nanosized metal oxides (Jin et al. 2011; Godinez et al. 2013).

The aim of this study was to synthesize a new adsorbent and to evaluate its adsorption capacity at different conditions. We selected nanocellulose as an adsorbent because this material is natural, inexpensive, and non-toxic. To improve its efficacy, nanocellulose was modified by amine groups, in order to interact with carboxyl groups of HA. The work was carried out in the Pajoohesh Lab, Yazd, Iran at November 2013.

\section{Materials and methods}

\section{Materials}

In order to synthesize nanocellulose, the raw cellulose manufactured by My Baby Company (Iran) was used. $\mathrm{N}$ (2-aminoethyl)-3-aminopropylmethyldimethoxysilane (AEADMS) was provided from Sigma-Aldrich Company (St Louis, MO, USA). Other chemicals including nitric acid, sulfuric acid, sodium hydroxide $(\mathrm{NaOH})$, and dimethylsulfoxide (DMSO) were sourced from Merck Company, Germany.
Nanocellulose synthesis

For nanocellulose synthesis, acid hydrolysis method was used according to Loelovich et al. with some modifications (Loelovich 2012). Before hydrolysis, $1 \mathrm{~g}$ raw cellulose was treated with $25 \mathrm{~mL}$ of $5 \mathrm{M} \mathrm{NaOH}$ at $37^{\circ} \mathrm{C}$ for $1 \mathrm{~h}$, and then rinsed with distilled water (DW). In the next step, $25 \mathrm{~mL}$ of $1 \mathrm{M}$ DMSO was added to $\mathrm{NaOH}$-treated cellulose, and incubated at $37{ }^{\circ} \mathrm{C}$ for $1 \mathrm{~h}$, too. Then, DMSOtreated cellulose was washed three times with DW and used for the next step. One gram of $\mathrm{NaOH}-\mathrm{DMSO}$-treated cellulose was added to $1 \mathrm{~mL}$ of acid mixture $(70 \% \mathrm{v} / \mathrm{v})$ and incubated at room temperature for $30 \mathrm{~min}$. The acid mixture had sulfuric acid (85\% v/v) and nitric acid (5\% $\mathrm{v} / \mathrm{v})$. To complete hydrolysis, some droplets of $90 \% \mathrm{v} / \mathrm{v}$ sulfuric acid were added, until the milky color of cellulose was removed. Then, $2 \mathrm{~mL}$ of $5 \mathrm{M} \mathrm{NaOH}$ was gently added to hydrolyzed cellulose, shaken for $5 \mathrm{~min}$, centrifuged at 3,000 rpm for $5 \mathrm{~min}$, and then nanocellulose pellets were washed by DW three times. In the final step, nanocellulose at concentration of $500 \mu \mathrm{g} / \mathrm{mL}$ was prepared in DW, shaken for $5 \mathrm{~min}$, and stored in $5^{\circ} \mathrm{C}$.

Modification of nanocellulose

To modify nanocellulose, $10 \mathrm{~mL}$ of nanocellulose at concentration of $500 \mu \mathrm{g} / \mathrm{mL}$ was added to $10 \mathrm{~mL}$ of $4 \% \mathrm{v} / \mathrm{v}$ AEADMS, incubated for $24 \mathrm{~h}$ at $37{ }^{\circ} \mathrm{C}$, and centrifuged at $5,000 \mathrm{rpm}$ for $15 \mathrm{~min}$. The pellet (amine-modified nanocellulose) was washed with DW, and its serial concentrations $(1,000,500,250,125$, and $62 \mu \mathrm{g} / \mathrm{mL})$ were prepared in DW and stored at $4{ }^{\circ} \mathrm{C}$.

Characterization of amine-modified nanocellulose

The structure, size distribution, and surface composition of amine-modified nanocellulose were investigated by transmission electron microscopy (TEM) (Hitachi, Japan), dynamic light scattering (DLS) (Malvern Instruments, Italy), and Fourier transform infrared spectroscopy (FTIR) (ELICO, India), respectively. For DLS, the viscosity of amine-modified nanocellulose was obtained by DLS apparatus, and then analysis was carried out at $25{ }^{\circ} \mathrm{C}$ after stabilization. For FTIR, all samples including nanocellulose, AEADMS, and amine-modified nanocellulose were dried on $\mathrm{KBr}$ block, and their adsorptions were read at $500-3,500 \mathrm{~cm}^{-1}$.

The effect of different parameters on the adsorption

To investigate the effect of various conditions on the adsorption, different parameters (e.g., concentration, 
Fig. 1 The structure of nanocellulose (a) and AEADMS (b) obtained from HyperChem software. In this study, a 9-unit cellulose was considered as nanocellulose
Fig. 2 The structure of humic acid as displayed by HyperChem software
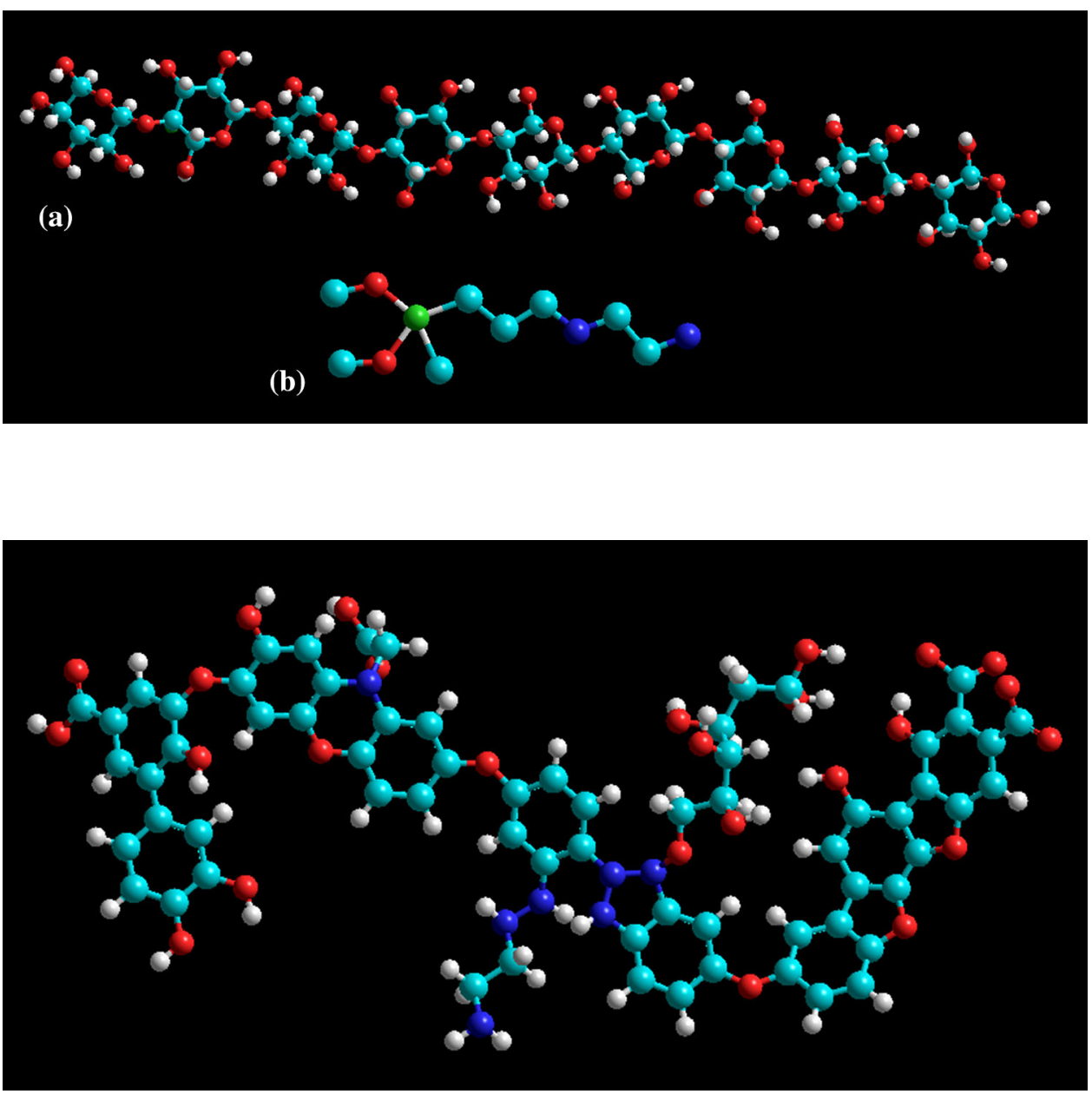

temperature, incubation times, and $\mathrm{pH}$ ) were studied. In the first group, one $\mathrm{mL}$ of serial concentrations of aminemodified nanocellulose was separately added to $1 \mathrm{~mL}$ of $\mathrm{HA}$ at concentration of $40 \mu \mathrm{g} / \mathrm{mL}$ at $\mathrm{pH} 7$, and separately incubated for $5 \mathrm{~min}$ at $4,25,37^{\circ} \mathrm{C}$, and $50{ }^{\circ} \mathrm{C}$. In the second group, serial concentrations of amine-modified nanocellulose and $40 \mu \mathrm{g} / \mathrm{mL} \mathrm{HA}$ at $\mathrm{pH} 7$ were separately incubated at $25^{\circ} \mathrm{C}$ for $5,10,15$, and $20 \mathrm{~min}$. In the third group, serial concentrations of amine-modified nanocellulose and $40 \mu \mathrm{g} / \mathrm{mL} \mathrm{HA}$ at different $\mathrm{pH}(2,5,7,9$, and 12) were separately incubated at $25{ }^{\circ} \mathrm{C}$ for $5 \mathrm{~min}$. In the fourth group, serial concentrations of HA $(40,60,80,100 \mu \mathrm{g} / \mathrm{mL})$ were incubated with $1,000 \mu \mathrm{g} / \mathrm{mL}$ amine-modified nanocellulose at optimum $\mathrm{pH}$, incubation time, and temperature which were obtained from three initial experiments. After incubation, all tubes were centrifuged at 10,000 rpm for 5 min, and optical density (OD) of supernatant was read by UV-visible spectrophotometer (ELICO, India) at $254 \mathrm{~nm}$. The adsorption percent $(\%)$ was measured by the adsorption equation. As negative control, HA was not incubated with amine-modified nanocellulose.

Adsorption $\%=\left(\mathrm{OD}_{\text {test }}-\mathrm{OD}_{\text {control }}\right) \times 100 / \mathrm{OD}_{\text {control }}$

Molecular dynamic (MD) simulation

Initial structures of nanocellulose (Fig. 1a), AEADMS (Fig. 1b), HA (Fig. 2), and amine-modified nanocellulose (Fig. 3) were performed by HyperChem Professional 8.0.3 software (Hypercube, Inc., USA) on an Acer laptop with CPU B960. The MD simulations were carried out with the Ascalaph Designer 1.8.69 software on the Inspur Cluster. In this study, force field and topology parameters were assigned from AMBER 99. Also, TIP3P water model with a cubic box (10 $\AA$ ) was used to solvate the amine-modified nanocellulose and HA. The cutoff distance of electrostatic interaction was $10 \AA$, and Van der Waals interactions were turned off between 12-14 A. Firstly, the energy of the whole system was minimized with 1,000 steps with hybrid 
Fig. 3 The structure of aminemodified nanocellulose after geometry optimization, prepared by HyperChem software

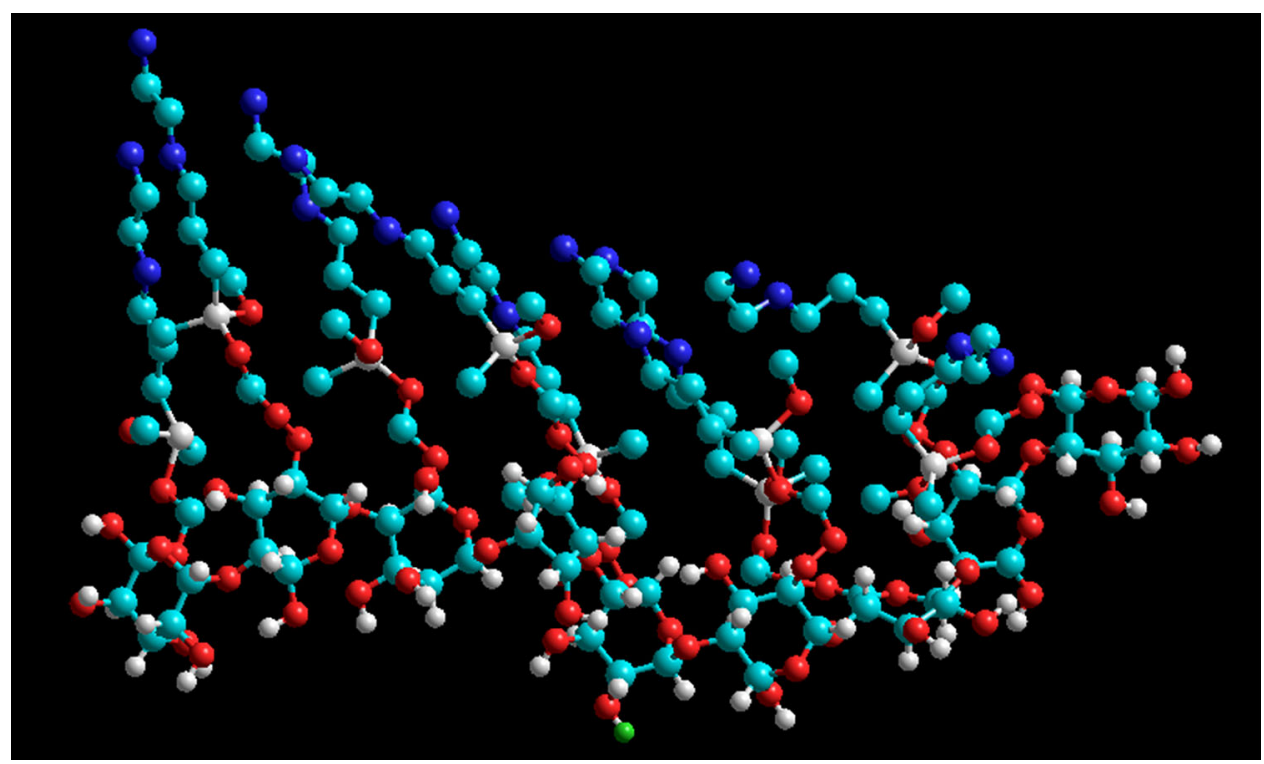

(a)

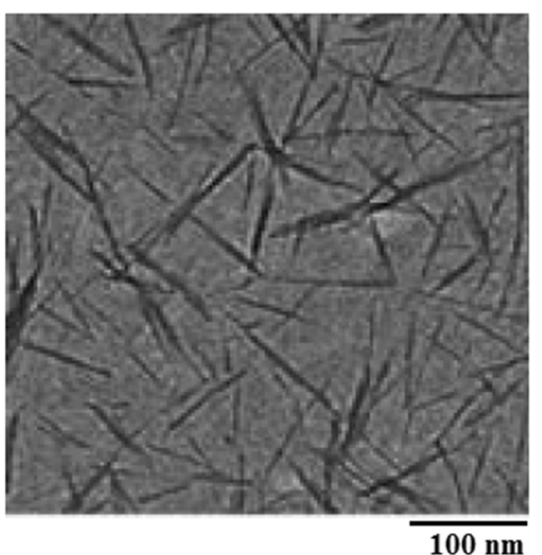

(b)

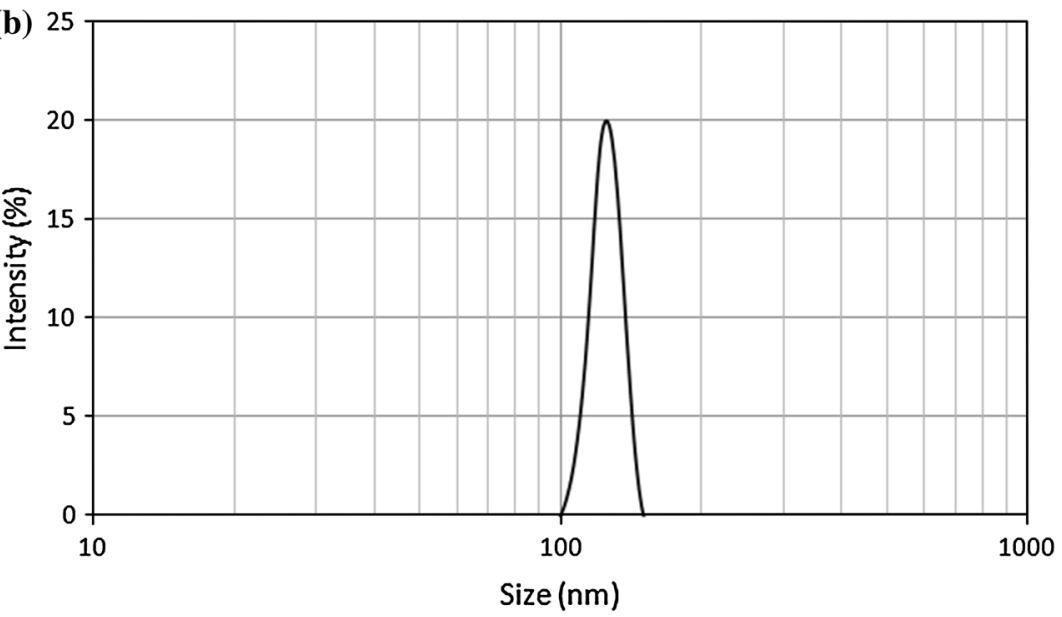

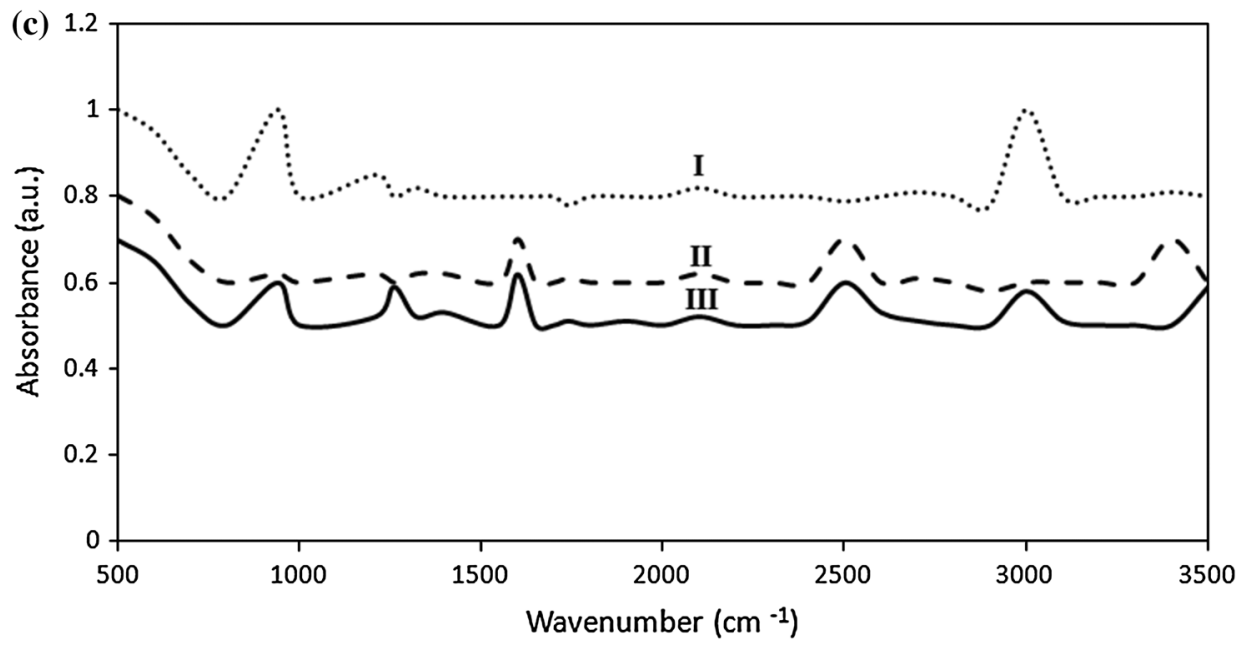

Fig. 4 The characterization results. The TEM image (a) and DLS graph (b) of amine-modified nanocellulose, also with the FTIR spectrum (c) of nanocellulose (I), AEADMS (II), and amine-modified nanocellulose (III) 

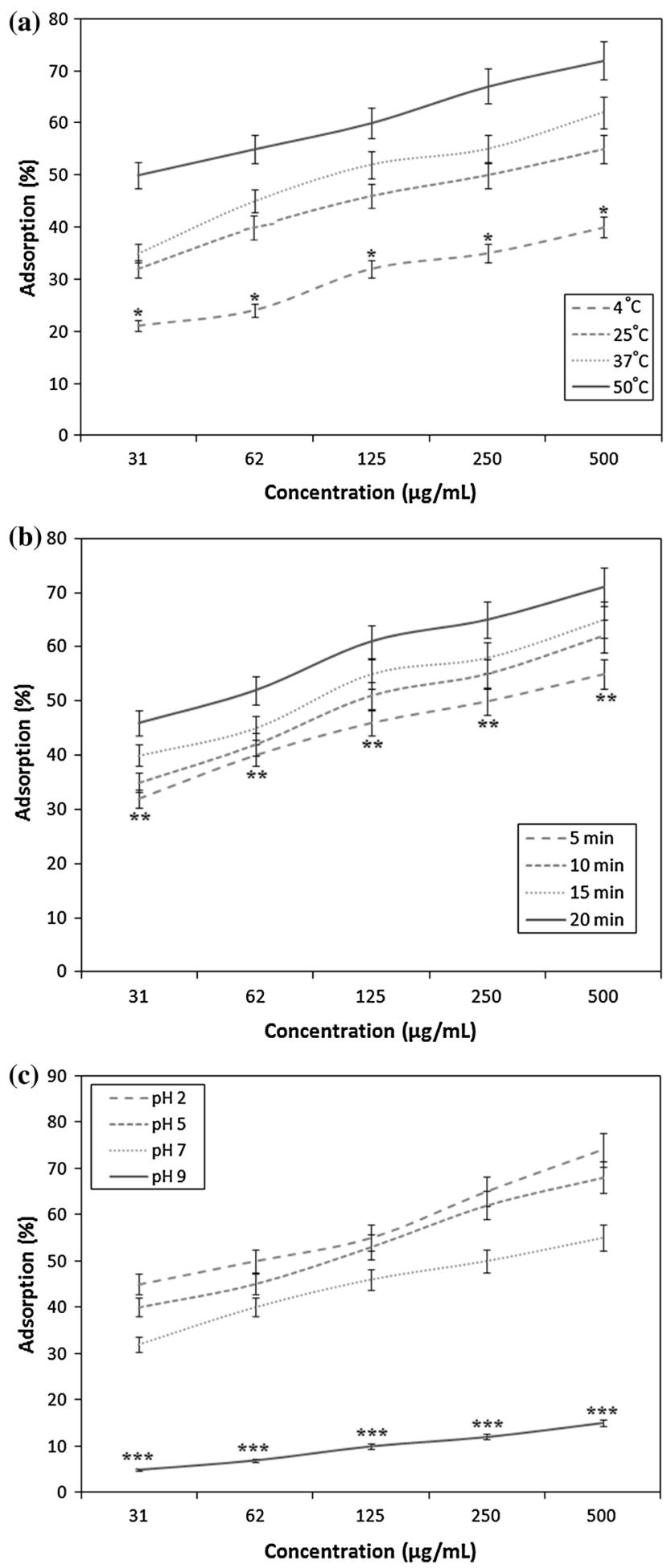

Lui Storey and Conjugate Descent (gradient $=0.001$ and iteration $=100$ ), and then MD simulation was carried out for $1,000 \mathrm{ps}$ in NVT ensemble at $298 \mathrm{~K}$. At the end of simulation, different parameters such as interaction energy, potential energy, and root-mean-square displacement (RMSD) were obtained from simulation software. Also, the
4Fig. 5 The effects of temperature (a), incubation time (b), and $\mathrm{pH}$ (c) on the humic acid adsorption. In the (a) section, temperature was variable and the other parameters were constant $(\mathrm{pH}=7$, incubation time $=5 \mathrm{~min}$ ). In the (b) section, incubation time was variable and the other parameters were fixed $\left(\mathrm{pH}=7\right.$, temperature $\left.=25^{\circ} \mathrm{C}\right)$. In the (c) section, $\mathrm{pH}$ was variable and other two parameters were constant (incubation time $=5$, temperature $=25^{\circ} \mathrm{C}$ ). $* P<0.05$ when comparing the adsorption at $4,25,37{ }^{\circ} \mathrm{C}$ for the same concentration. $* * P<0.05$ when comparing the adsorption at $15 \mathrm{~min}$ and $20 \mathrm{~min}$ for the same concentration. $* * * P<0.05$ when comparing

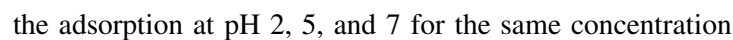

ultimate structure of HA and amine-modified nanocellulose were captured at the final step of simulation.

Statistical analysis

The results are shown as the mean \pm standard deviation (SD) with three independent tests. Parametric test (Student's $t$ test) was applied to evaluate the significant difference between groups by means of SPSS software (v.16.0 for Windows; SPSS Inc., USA). $P<0.05$ was considered as significant difference.

\section{Results and discussion}

\section{Characterization}

The TEM image and DLS graph of amine-modified nanocellulose are shown in Fig. 4a, b, respectively. Based on TEM image, amine-modified nanocellulose was approximately rod-like $(100 \mathrm{~nm} \times 5 \mathrm{~nm})$. DLS graph showed that the size distribution of amine-modified nanocellulose was near $100-150 \mathrm{~nm}$. The FTIR spectrum of nanocellulose (I), AEADMS (II), and amine-modified nanocellulose (III) are shown in Fig. 4c. As is seen, nanocellulose had sharp peaks at 940 and $3,000 \mathrm{~cm}^{-1}$, but AEADMS showed sharp peaks at 1,600, 2,500, and $3,400 \mathrm{~cm}^{-1}$. As is observed, both specific peaks of nanocellulose and AEADMS were observed in the spectrum of amine-modified nanocellulose. Generally, the spectrum of amine-modified nanocellulose shows the attachment of AEADMS to the nanocellulose.

The effect of various conditions on the adsorption

The effects of temperature, incubation time, and $\mathrm{pH}$ on the adsorption are shown in Fig. 5a, b, c, respectively. As is shown, when temperature and incubation time were increased, the adsorption was also raised. In contrast, the adsorption was decreased with increase in $\mathrm{pH}$. In all experiments, the highest and the least adsorption were shown at amine-modified nanocellulose concentration of 


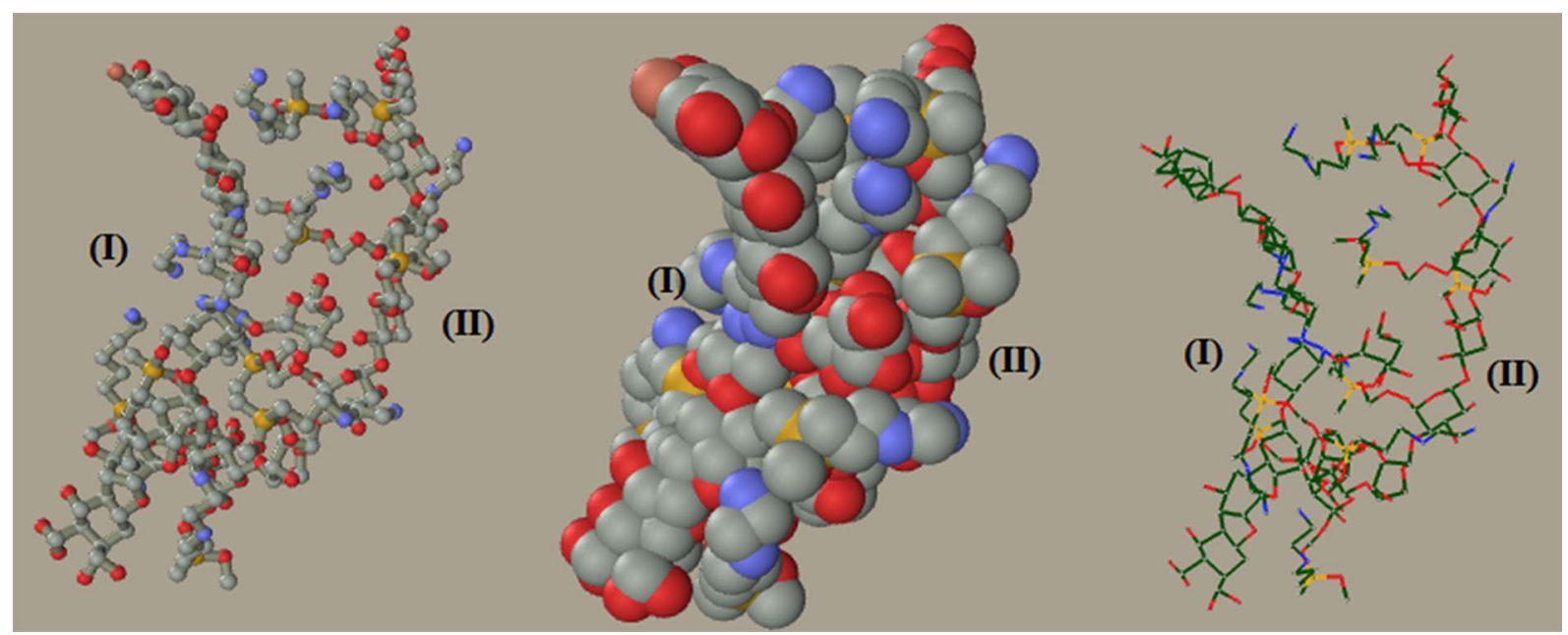

Fig. 6 The 3-dimensional structure of humic acid (I) and amine-modified nanocellulose (II) at the final simulation by the HyperChem software. These structures are shown as ball and stick (left), Corey-Pauling-Koltun (CPK) (middle) and CPK wire frame (right)

$500 \mu \mathrm{g} / \mathrm{mL}$ and $31 \mu \mathrm{g} / \mathrm{mL}$, respectively. This study showed that HA adsorption was dose-dependent. As is seen, significant differences were found between $\mathrm{HA}$ adsorption at $4{ }^{\circ} \mathrm{C}$ versus 25,37 , and $50{ }^{\circ} \mathrm{C}(P<0.05)$. Such difference was also seen between HA adsorption after 5 versus 10,15 , and $20 \mathrm{~min}(P<0.05)$. Likewise, there were significant differences between HA adsorption at $\mathrm{pH} 9$ versus $\mathrm{pH} 7$, $\mathrm{pH} 5$, and $\mathrm{pH} 2(P<0.05)$. Details of statistical analysis are demonstrated on the figures. This study showed that the maximum adsorption was approximately $98 \%$, with optimum conditions, temperature $=50{ }^{\circ} \mathrm{C}, \mathrm{pH}=2$, incubation time $=20 \mathrm{~min}$, concentration of amine-modified nanocellulose $=500 \mu \mathrm{g} / \mathrm{mL}, \quad$ and concentration of $\mathrm{HA}=40 \mu \mathrm{g} / \mathrm{mL}$.

According to results, the adsorption was increased when incubation time and temperature were raised, which may be due to higher interaction between HA and amine-modified nanocellulose. In contrast, the adsorption was decreased with increase in $\mathrm{pH}$. It may be that amine groups of amine-modified nanocellulose and carboxyl groups of HA are differently affected by basic and acidic conditions. This phenomenon changes electrostatic forces and leads to different adsorption at different $\mathrm{pH}$. There is no published paper to show the application of amine-modified nanocellulose for absorption of HA, and the present study is the first report.

In this section, we will discuss on other amine-modified adsorbents which have been investigated in previous studies. Zhang et al. studied mechanisms and kinetics of HA adsorption onto chitosan-coated granules. They indicated that the adsorption was strongly $\mathrm{pH}$-dependent, i.e., high amounts of HA were adsorbed at neutral and acidic conditions but the adsorption was reduced remarkably with increase in $\mathrm{pH}$. According to X-ray photoelectron spectroscopy experiment, the amine groups of chitosan were protonated after HA adsorption and led to organic complex formation between the protonated amino groups and HA (Zhang and Bai 2003). Anirudhan et al. worked on surfactant-modified bentonite (SMB) for the removal of HA from wastewaters. They showed that SMB had very high (99\%) adsorption rate at acidic condition. It was indicated that the maximum adsorption capacity was $73.52 \mu \mathrm{mol} / \mathrm{g}$ at $\mathrm{pH}$ 3.0. Also, the adsorption of HA was less with increase of ionic strength due to the formation of surface complexes on SMB. They declared that SMB efficacy was not changed after three times of usage (Anirudhan and Ramachandran 2007). In another study, Anirudhan et al. studied on amine-modified polyacrylamide-bentonite composite for the adsorption of HA. In the study, amine modification was attained by direct-intercalation polymerization. They found that the maximum adsorption was $99.9 \%$ at $\mathrm{pH}$ range of 4.0-7.0. It was explained that the mechanism of adsorption was mainly through the complex formation between the protonated $\mathrm{NH} 2$ groups in amine-modified polyacrylamide-bentonite and the carboxyl groups in HA. A pseudo-second-order model was used to describe the kinetics of adsorption, and the adsorption was increased in higher temperatures, indicating endothermic nature of adsorption (Anirudhan et al. 2008). Zhan et al. used bilayer hexadecyltrimethyl ammonium bromidemodified zeolite (BHABMZ) to remove HA from aqueous solution. Their results showed that BHABMZ had higher adsorption rate than the natural zeolite. They indicated that the coexistence of $\mathrm{Ca}^{2+}$ in solution favored adsorption onto BHABMZ. On the other hand, adsorption capacity was decreased with increasing $\mathrm{pH}$. They indicated that the adsorption of HA was well fitted with pseudo-second-order kinetic model and the Langmuir model (Zhan et al. 2011).

Tanga et al. declared that amine-functionalized magnetic mesoporous composite microspheres had high 
(a)

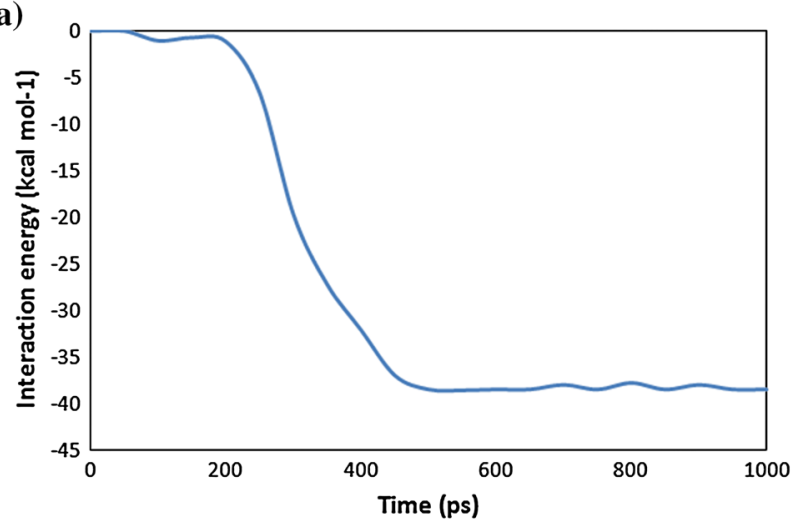

(b)

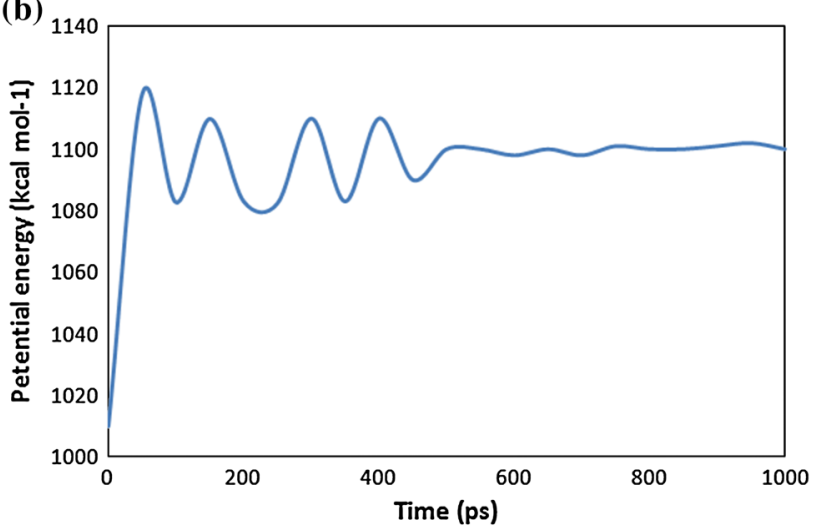

(c)

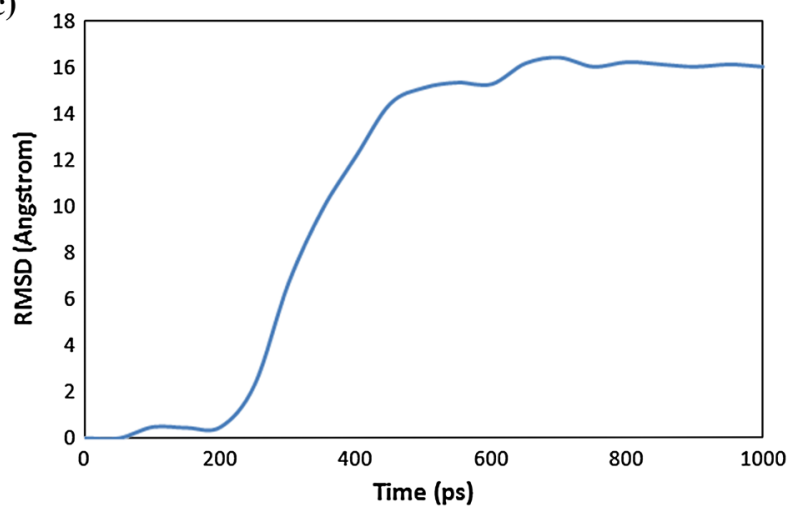

Fig. 7 The molecular dynamics simulation results: Interaction energy (a), potential energy (b) and RMSD (c). RMSD: root-meansquare displacement

adsorption affinity to HA with a maximum adsorption capacity. The Freundlich model and the pseudo-secondorder kinetic were well describing the adsorption. These studies indicated that amine group could easily interact with carboxyl groups of HA, and the fact leads to HA adsorption (Tanga et al. 2012). In consistent with these studies, we showed that amine-modified nanocellulose is a good HA adsorbent.

Regarding the application of nanoparticles for removing $\mathrm{HA}$, Qiao et al. showed that nano-photocatalyst $\mathrm{Fe}_{2} \mathrm{O}_{3} /$ $\mathrm{TiO}_{2}$ could remove HA. They explained that degradation and decolorization of HA were obtained with higher efficiency in acidic condition. First-order reaction kinetic was suitable for photocatalytic degradation (Qiao et al. 2003). Yang et al. worked on the adsorption behavior of $\mathrm{HA}$ by $\mathrm{TiO}_{2}, \mathrm{SiO}_{2}, \mathrm{Al}_{2} \mathrm{O}_{3}$, and $\mathrm{ZnO}$ nanoparticles. It was declared that $\mathrm{TiO}_{2}, \mathrm{Al}_{2} \mathrm{O}_{3}$, and $\mathrm{ZnO}$ nanoparticles could absorb $\mathrm{HA}$ but $\mathrm{SiO}_{2}$ nanoparticle had no efficacy. They discussed that HA adsorption was mainly induced by electrostatic forces and ligand exchange between HA and nanoparticle surfaces (Yang et al. 2009). According to previous studies, different kinetic models were introduced to predict the mechanism of adsorption [including pseudofirst-order model, pseudo-second-order model, first-order reversible reaction model, Weber and Morris sorption kinetic model, external mass transfer model, Elovich's model, first-order equation of Bhattacharya and Venkobachar, and Ritchies's equation (Febrianto et al. 2009)].

MD simulation

Figure 6(I) and (II) show the structure of amine-modified nanocellulose and HA at the final simulation, respectively. These figures demonstrate that HA was absorbed by aminemodified nanocellulose. The interaction energy, potential energy, and RMSD are shown in Fig. 7a, b, and c, respectively. As is seen, interaction energy was reduced and equilibrated at $-40 \mathrm{kcal} / \mathrm{mol}$, but potential energy was increased and balanced at near $1,100 \mathrm{kcal} / \mathrm{mol}$. Similar to potential energy, RMSD was increased and equilibrated at near 16 angstrom. Generally, these findings confirm the adsorption of HA by amine-modified nanocellulose.

In this study, MD simulation was also used to show interaction of HA and amine-modified nanocellulose molecules. All simulation results (e.g., interaction energy, potential energy, and RMSD) approved the adsorption of HA by amine-modified nanocellulose, too. Regarding its molecular structure, HA was fitted with amine-modified nanocellulose. Based on simulation data, the authors hypothesize that carboxyl and hydroxyl groups of HA interact with amine group of amine-modified nanocellulose, which may lead to a new compound. We propose that electrostatic forces are the main mechanism of adsorption. There is no computer-based study to compare results, and this study is the first report. Shih et al. showed the adsorption kinetics and thermodynamic properties of HA by toluene. They indicated that MD simulation is an alternative and powerful tool to understand the adsorption at the molecular level (Shih et al. 2006). Taken together, the adsorption of $\mathrm{HA}$ by amine-modified nanocellulose was depended on $\mathrm{pH}$, temperature, incubation time, HA concentration, and aminemodified nanocellulose concentration. On the other hand, MD simulation showed the adsorption. The authors suggest that amine-modified nanocellulose must be studied in actual conditions to remove HA from wastewater. 


\section{Conclusion}

This study showed that the adsorption of HA by aminemodified nanocellulose was $\mathrm{pH}-$, temperature-, dose-, and time-dependent. Furthermore, MD simulation confirmed HA adsorption. The authors propose that amine-modified nanocellulose may be used for removal of HA from wastewater.

Acknowledgments This study was financially supported by $\mathrm{Pa}$ joohesh Medical Lab, Yazd, Iran (grant number 3-2013). The authors thank the laboratory staff of the Yazd Pajoohesh medical lab.

Conflict of interest No conflict of interest is addressed.

\section{References}

Anirudhan TS, Ramachandran M (2007) Surfactant-modified bentonite as adsorbent for the removal of humic acid from wastewaters. Appl Clay Sci 35(3-4):276-281

Anirudhan TS, Suchithra PS, Rijith S (2008) Amine-modified polyacrylamide-bentonite composite for the adsorption of humic acid in aqueous solutions. Colloids Surf A 326(3):147-156

Bazrafshan E, Biglari H, Hossein Mahvi A (2012) Humic acid removal from aqueous environments by electrocoagulation process using iron electrodes. J Chem 9(4):2453-2461

Davis JA, Gloor R (1981) Adsorption of dissolved organics in lake water by aluminum oxide. Effect of molecular weight. Environ Sci Technol 15:1223-1229

Febrianto J, Kosasiha AN, Sunarsob J, Jua Y, Indraswati N, Ismadji S (2009) Equilibrium and kinetic studies in adsorption of heavy metals using biosorbent: a summary of recent studies. J Hazard Mater 162:616-645

Giasuddin AM, Kanel S, Choi H (2007) Adsorption of humic acid onto nanoscale zerovalent iron and its effect on arsenic removal. Environ Sci Technol 41:2022-2027

Godinez IG, Darnault CJ, Khodadoust AP, Bogdan D (2013) Deposition and release kinetics of nano-TiO2 in saturated porous media: effects of solution ionic strength and surfactants. Environ Pollut 174:106-113

Jin C, Tang Y, Yang FG, Li XL, Xu S, Fan XY, Huang YY, Yang YJ (2011) Cellular toxicity of TiO2 nanoparticles in anatase and rutile crystal phase. Biol Trace Elem Res 141(1-3):3-15
Jonglertjunya W, Lertchutimakul T (2012) Equilibrium and kinetic studies on the adsorption of humic acid by activated sludge and Bacillus subtilis. Songklanakarin J Sci Technol 34(6):669-677

Liang L, Luo L, Zhang S (2011) Adsorption and desorption of humic and fulvic acids on $\mathrm{SiO} 2$ particles at nano-and micro-scales. Colloids Surf A 384:126-130

Lin SH, Juang RS (2002) Heavy metal removal from water by sorption using surfactant-modified montmorillonite. J Hazard Mater 92(3):315-326

Loelovich M (2012) Optimal conditions for isolation of nanocrystalline cellulose particles. Nanosci Nanotechnol 2:9-13

Moussavi G, Talebi S, Farrokhi M, Sabouti RM (2011) The investigation of mechanism, kinetic and isotherm of ammonia and humic acid co-adsorption onto natural zeolite. Chem Eng J 171:1159-1169

Qiao S, Sun DD, Tay JH, Easton C (2003) Photocatalytic oxidation technology for humic acid removal using a nano-structured $\mathrm{TiO} 2 / \mathrm{Fe} 2 \mathrm{O} 3$ catalyst. Water Sci Technol 47(1):211-217

Qin X, Liu F, Wang G (2012) Fractionation and kinetic processes of humic acid upon adsorption on colloidal hematite in aqueous solution with phosphate. Chem Eng J 209:458-463

Shih YH, Lin JS, Wu SC, Lee LF (2006) Molecular dynamic simulations of the sorption of toluene in a dry humic acid model: a preliminary study. Colloids Surf A Physicochem Eng Asp 275:183-186

Tanga Y, Lianga S, Yua S, Gaoa N, Zhanga J, Guoa H, Wang Y (2012) Enhanced adsorption of humic acid on amine functionalized magnetic mesoporous composite microspheres. Colloids Surf A 406:61-67

Terdkiatburana T, Wang S, Tadé MO (2008) Competition and complexation of heavy metal ions and humic acid on zeolitic MCM-22 and activated carbon. Chem Eng J 139(3):437-444

Trump VJI, Sun Y, Coates JD (2006) Microbial interactions with humic substances. Adv Appl Microbiol 60:55-96

Wang S, Terdkiatburana T, Tade' MO (2008) Adsorption of Cu (II), $\mathrm{Pb}$ (II) and humic acid on natural zeolite tuff in single and binary systems. Sep Purif Technol 62:64-70

Yang K, Lin D, Xing B (2009) Interactions of humic acid with nanosized inorganic oxides. Langmuir 25(6):3571-3576

Zhan Y, Lin J, Qiu Y, Gao N, Zhu Z (2011) Adsorption of humic acid from aqueous solution on bilayer hexadecyltrimethyl ammonium bromide-modified zeolite. Front Environ Sci Eng China 5(1):65-75

Zhang X, Bai R (2003) Mechanisms and kinetics of humic acid adsorption onto chitosan-coated granules. J Colloid Interface Sci 264(1):30-38 